\title{
Surface Pressure of the Mine Refuge Shelter in Underground Gas Explosion
}

\author{
Zijun Zheng \\ Zhejiang Business Technology Institute \\ Ninghai China 13757137100 \\ zzj0571@sina.com
}

\begin{abstract}
The underground gas explosion test model to detect intensity of the mine refuge shelter is simulated through LSDYNA to obtain the surface pressure of the mine refuge shelter in underground gas explosion, using the TNT to replace the mixture gas. Pressure distribution of the front shelter is descending from the bottom to the top, and from the middle to both sides, which is about $0.4410 \sim 0.5326 \mathrm{MPa}$, the duration is $242.5 \mathrm{~ms}$. After the maximum pressure peak, there are several smaller pressure peaks. Pressure distribution of the back shelter is descending from the bottom to the top, and from the middle to both side, which is about 0.2027 0.3144MPa. With the distance to the front increases, pressure distribution of the top and side shelter is descending, but the extent of descending is small, which is about 0.27MPa.
\end{abstract}

Key words-Pressure distribution;TNT equivalent method; LSDYNA; Mine Refuge Shelters; gas explosion

\section{INTRODUCTION}

The mine refuge shelter is a sealing device for mine workers refuge when gas explosion, fire disaster or water inrush accident happens. The first protecting wall of the shelter is the shell .When gas explosion, fire disaster or water inrush accident happens, the whole shelter would not work if the shell was broken. So the strength of the shell should be able to resist the pressure of the gas explosion shock wave to make sure internal facilities of shelter will be effective when accident happens. The main design methods of the mine refuge shelter are parameter analogy design and experience design. For a better designing of shell, it is necessary to analyze the pressure conditions of gas explosion. Now, the main detection is underground explosion test of the mine refuge shelter which is taken in large underground explosion roadway of Chongqing Research Institute of Coal Scientific Research Institute. The cross-sectional area of the roadway is $7.2 \mathrm{~m}^{2}$, and the length is $896 \mathrm{~m}$. Roadway closed at one end and outflow at the other end. Explosion gas volume is $200 \mathrm{~m}^{3}$, density is $9.5 \%[1]$. The distance between the mine refuge shelter and explosion gas is $100 \mathrm{~m}$.

\section{The establishment of the explosion source}

The main methods of gas explosion overpressure research are experimental study and theory research. The theory research methods are TNT equivalent method, multi-energy
Junhao Li

Key Laboratory of E\&M (Zhejiang University of Technology), Ministry of Education \& Zhejiang Province Hangzhou China 13588823304 junhaoli2006@sina.com

model and numerical simulation method. On the basis of TNT equivalent method, this paper use LS-DYNA to establish the numerical simulation model of gas explosion wave propagation law in underground roadway.

\section{A. Determine the quality of TNT}

The formula of TNT equivalent method as below:

$$
W_{T N T}=\frac{\alpha W_{\mathrm{f}} H_{f}}{H_{T N T}}
$$

$W_{T N T}$ is the equivalent mass, $\mathrm{Kg} ; \alpha$ is the equivalent factor of TNT, 0.03 ( U.K.HSH(1986)recommendation); ${ }{ }_{f}$ is the mass of mixed gas; $H_{f}$ is the heat of combustion of fuel, $\mathrm{MJ} / \mathrm{Kg}$, the heat of combustion of methane is $890 \mathrm{KJ} / \mathrm{mol}$, as $55.625 \mathrm{MJ} / \mathrm{Kg} ;{ }_{T N T}$ is the explosion heat of TNT, $\mathrm{MJ} / \mathrm{Kg}$, in this paper it is $4.552 \mathrm{MJ} / \mathrm{Kg}[2]$. When gas density was $9.5 \%$, the density of mix air would be $1.236 \mathrm{Kg} / \mathrm{m}^{3}$.So the equivalent mass of TNT is $91 \mathrm{Kg}$.

\section{B. The Establishment Of Finite Element Model}

Assumed that ground and roadway wall are rigid wall boundaries. The roadway at the outflow uses the outflow boundary. The simulation of roadway length is $300 \mathrm{~m}$; The density of TNT is $1600 \mathrm{Kg} / \mathrm{m}^{3}$. So the volume of TNT is $0.057 \mathrm{~m}^{3}$. The TNT placed in the center of roadway sealed section; We build a half model to calculation because of symmetry. The simulation model is shown in figure 1. TNT simulated by JWL state equation and air simulated by linear polynomial state equation[3] both use multiple substance ALE algorithm simulation.

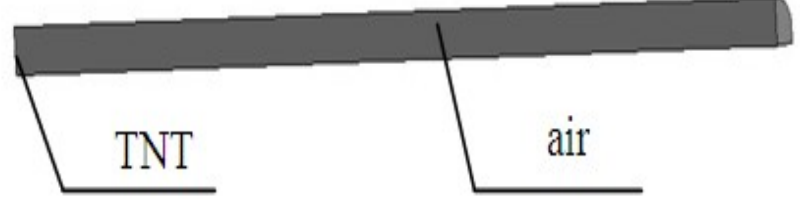

Figure 1 Simulation model 
C. The comparison between simulative values and experimental values

The comparison between simulative values and experimental values is shown in table 1 .

The explosion of TNT belongs to condensed explosive while the explosion of gas belongs to gas detonation. The initial overpressure of TNT explosion is higher than gas explosion's, and its attenuation speed is also faster than gas explosion's. But the overpressure values of them would be close after $80 \mathrm{~m}$. Simulative values and experimental values are very close. In this paper, the distance between the mine refuge shelter and the explosion gas is $100 \mathrm{~m}$,so we can use TNT to replace the gas explosion.

TABLE 1 THE COMPARISON BETWEEN SIMULATION AND EXPERIMENTAL VALUES

\begin{tabular}{|c|c|c|c|}
\hline $\begin{array}{c}\text { distance } \\
(\mathbf{m})\end{array}$ & $\begin{array}{c}\text { Simulatiive } \\
\text { valu } \\
(\mathbf{M P a})\end{array}$ & $\begin{array}{c}\text { Experimental } \\
\text { value (Mpa) }\end{array}$ & error \\
\hline 40 & 0.4921 & 0.2880 & 0.709 \\
\hline 60 & 0.3736 & 0.2843 & 0.314 \\
\hline 80 & 0.3116 & 0.2723 & 0.1443 \\
\hline 100 & 0.2780 & 0.2620 & 0.016 \\
\hline 120 & 0.2527 & 0.2557 & 0.011 \\
\hline 140 & 0.2340 & 0.2497 & 0.062 \\
\hline 160 & 0.2198 & 0.2427 & 0.094 \\
\hline
\end{tabular}

\section{NUMERICAL SIMULATION}

Add the mine refuge shelter model into roadway model which is mentioned above. The mine refuge shelter model's width is $1800 \mathrm{~mm}$, and its total height is $1800 \mathrm{~mm}$, and its total length is $6700 \mathrm{~mm}$. The top of shelter is a circular arc whose radius is $1400 \mathrm{~mm}$. In order to simplify the calculation, we use the same cross section but solid structure to replace the shelter. The shelter is placed in the center of roadway model and is $100 \mathrm{~m}$ away from the explosion gas. We assume that the connection between the shelter and the ground is reliable. The cross section is shown in figure 2, and the finite element model is shown in figure 3.The material of the shelter is Q235 with plastic kinematic hardening model. The simulation time is $500 \mathrm{~ms}$.

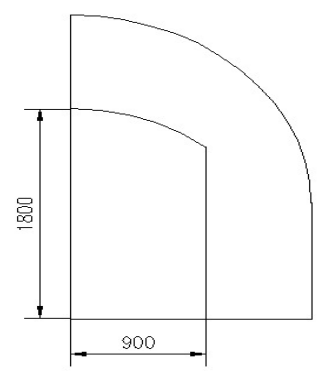

Figure 2 The cross section of refuge shelter

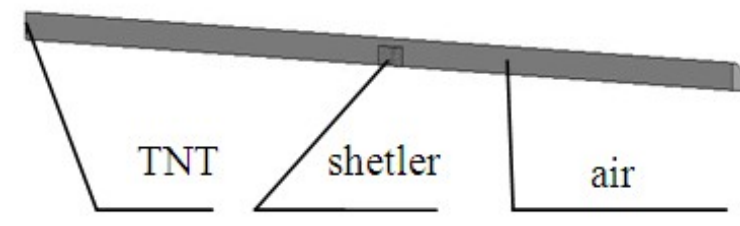

Figure 3 Finite element model

\section{THE PRESSURE ANALYSIS OF THE SHELTER}

\section{A. The front pressure}

We take the surface facing explosion gas as the front surface. The front pressure is shown in figure 4.

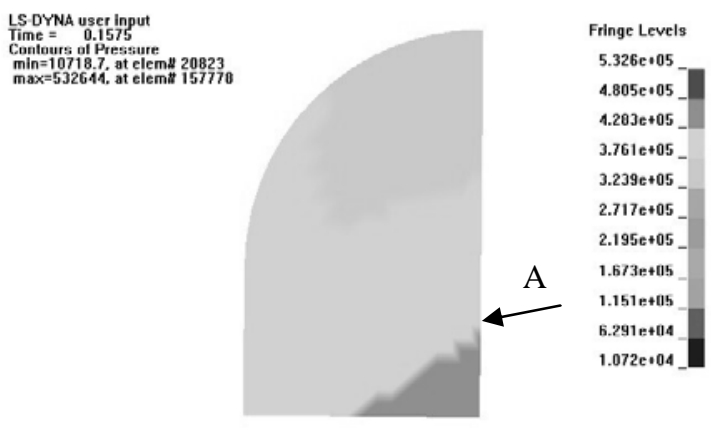

Figure 4 Front pressure distribution

The position of point $A$ is in the bottom center of the front whose distance to bottom is $500 \mathrm{~mm}$. The relationship of pressure-time is shown in figure 5 .

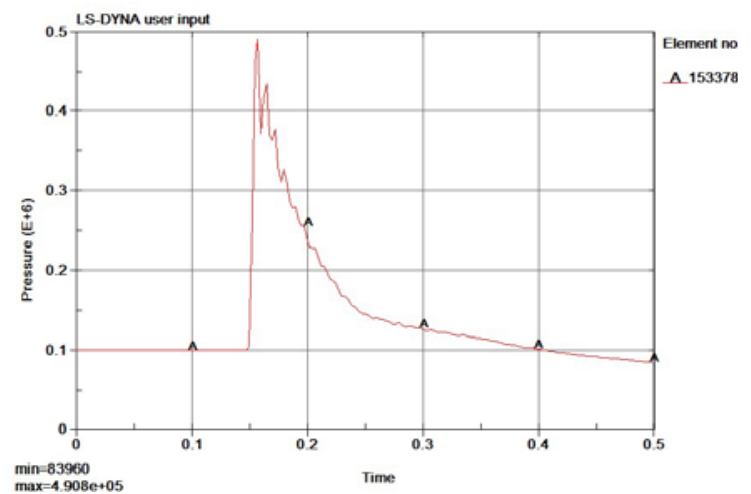

Figure 5 Point A pressure time curve

It is worked out to be that the shelter pressure decreases from bottom to top, and from center to both sides by analyzing of the front pressure. The maximum pressure of the shelter which is in the bottom centre is $0.5326 \mathrm{MPa}$. The minimum pressure which is in the top part of the shelter centre is $0.4410 \mathrm{MPa}$. The relationship of pressure-time of front points is similar to A. The arrival time of maximum pressure peaks is same, which is $157.5 \mathrm{~ms}$, but the maximum peak pressure is different. The duration of shock wave is $242.5 \mathrm{~ms}$; After the maximum peak pressure, there are several smaller pressure peaks because of roadway reflection, which is consistent with the fact. The front pressure of the shelter is much larger than 
$0.2780 \mathrm{MPa}$ in table 1 , which shows that the shelter have incentive effect on blast shock wave.

\section{B. The back pressure}

We take the surface which is back towards explosion source as the back surface. The back pressure is shown in figure 6 .

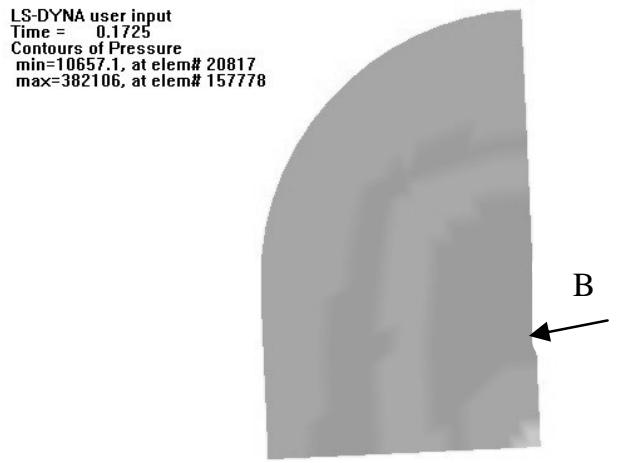

Fringe Levels

$3.821 \mathrm{e}+05$

$3.450 \mathrm{e}+05$

$3.078 \mathrm{e}+05$

$2.707 e+05$

$2.335 e+05$

$1.964 \mathrm{e}+05$

$1.592 \mathrm{e}+05$

$1.221 \mathrm{e}+05$

$8.495 \mathrm{e}+04$

$4.780 \mathrm{e}+04$

$1.066 \mathrm{e}+04$

Figure 6 Back pressure distribution

The location of point B is in back center, and its distance to bottom is $500 \mathrm{~mm}$. The pressure-time relationship is shown in figure 7.

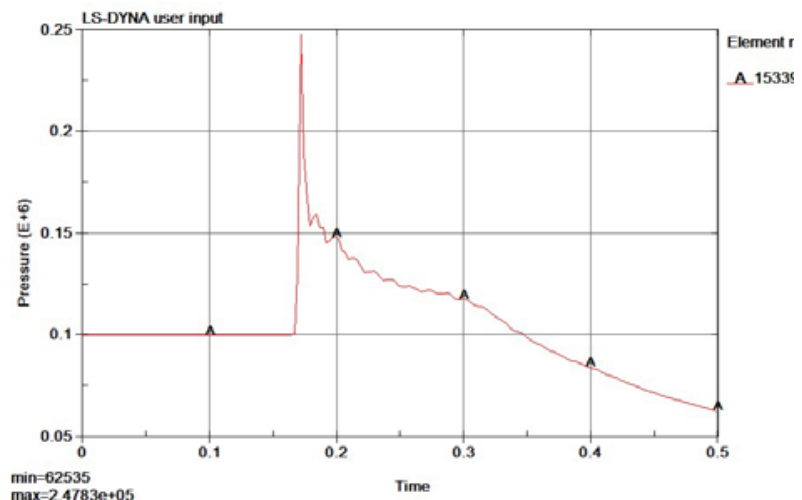

Figure 7 Point B pressure time curve

The pressure distribution of back is similar to the front pressure, decreasing from bottom to top, and from center to both sides. The maximum pressure which is in the bottom center is $0.3144 \mathrm{MPa}$. The minimum pressure which is in the top part is $0.2027 \mathrm{MPa}$.The relationship of pressure-time of back points is similar to $\mathrm{B}$. The arrival time of maximum pressure peaks is same, which is $172.5 \mathrm{~ms}$, but the maximum peak pressure is different. The maximum pressure peak decays quickly.

\section{The top and side pressure}

As the top of the shelter is a circular arc, this paper takes the top center points and the side points whose distance to bottom is $500 \mathrm{~mm}$ for research. Pressure values are shown in figure 8 , the abscissa is the distance between each point and the front of the shelter, and its unit is $\mathrm{M}$. The ordinate is the pressure, and its unit is $\mathrm{MPa}$.

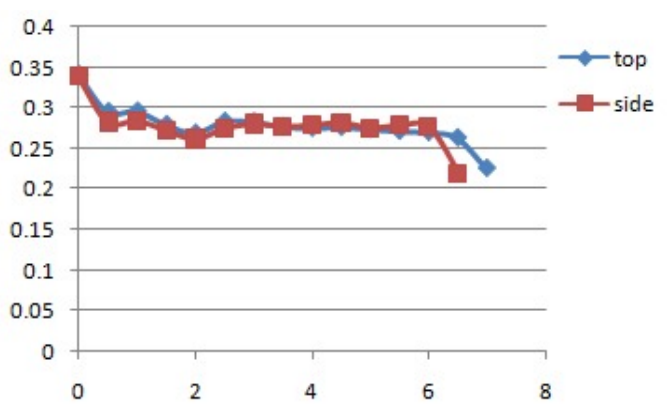

Figure 8 The top and side pressure-distance relation

Point $\mathrm{C}$ is in the top center whose distance to front is $3500 \mathrm{~mm}$, and the relationship of pressure- time is shown in figure 9. Point D is $500 \mathrm{~mm}$ away from the bottom, and is $3500 \mathrm{~mm}$ away from the front. The relationship of pressuretime is shown in figure 10 .

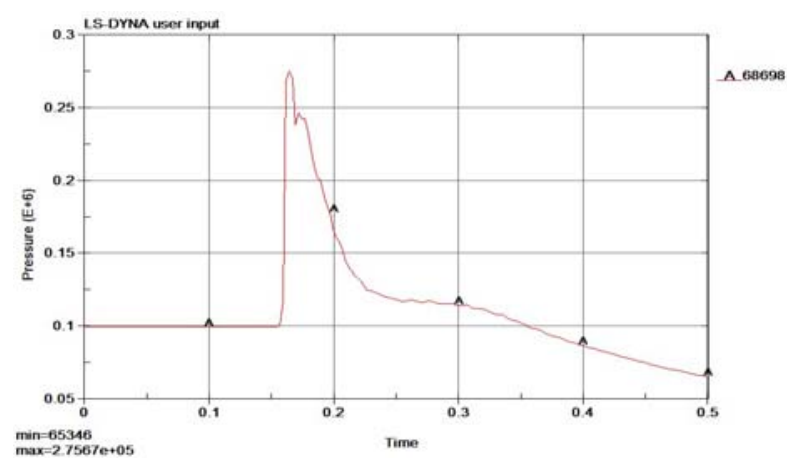

Figure 9 Point $\mathrm{C}$ pressure time curve

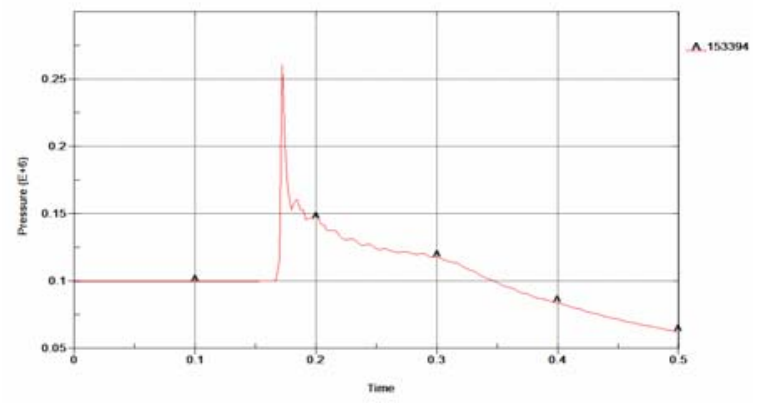

Figure 10 Point D pressure time curve

With the distance to front increases, top pressure and side pressure reduce, but the scope is very small, which is $0.27 \mathrm{MPa}$ basically. When the shock wave goes into the top surface and goes out of the top surface, pressure decreases faster, and both of them have an obvious pressure drop. The attenuation of peak pressure of the side is very fast. When the shock wave goes into the side surface and goes out of the side surface, the pressure is reduced quickly, and both of them have an obvious pressure drop.

\section{CONCLUSIONS}

a) We can use the $91 \mathrm{~kg}$ TNT to replace the $200 \mathrm{~m}^{3}$ mixture gas with concentration of $9.5 \%$ in the finite element model of the underground gas explosion using LS-DYNA. 
b) The front pressure of the shelter decreases from the bottom to top, and from the center to both sides. After the maximum peak pressure, there are several smaller pressure peaks. The pressure is about $0.4410 \sim 0.5326 \mathrm{MPa}$, and the duration is $242.5 \mathrm{~ms}$.

c) The back pressure decreases from the bottom to the top, and from the center to both sides. The pressure is about 0.2027 0.3144MPa.

d) The top and side pressures gradually reduce with the increase of the distance to the front, but the decrease rate is slow. The pressure is about $0.27 \mathrm{MPa}$.

\section{REFERENCES}

[1] XiaotaoFang, "The antiknock performance test research of mine refuge shelter ," mining safety and environmental protrction, 2010, pp. 25-30, (in Chines)

[2] BaoyanZhang,Zhangqianming,Huangfenglei.”detonation physics”. Ordnance industry press, 2006, pp.173. (in Chines)

[3] ShaoqianShi,Kangjiangong,Wangmian,Liuyun.”LS-DYNA engineering applications in the field of explosion and shock.china buliding industry press 2011, pp. 27-28. (in Chines)

[4] JingdeXu.Dissemination of the law and its influencing factors of the coal mine gas blast.resources and safety engineering college of china university of mining2003,6. (in Chines) 